\title{
Adherence with COVID-19 Preventive Measures and Associated Factors Among Residents of Dirashe District, Southern Ethiopia
}

This article was published in the following Dove Press journal: Patient Preference and Adherence

\author{
Agegnehu Bante $\mathbb{D}^{\prime}$ \\ Abera Mersha $\mathbb{D}^{\prime}$ \\ Azene Tesfaye $\mathbb{D}^{2}$ \\ Behailu Tsegaye $\mathbb{D}^{3}$ \\ Shitaye Shibiru' \\ Gistane Ayele (iD ${ }^{4}$ \\ Meseret Girma ${ }^{4}$ \\ 'School of Nursing, College of Medicine \\ and Health Sciences, Arba Minch \\ University, Arba Minch, Ethiopia; \\ ${ }^{2}$ Department of Medical Laboratory \\ Sciences, College of Medicine and Health \\ Sciences, Arba Minch University, Arba \\ Minch, Ethiopia; ${ }^{3}$ School of Medicine, \\ College of Medicine and Health Sciences, \\ Arba Minch University, Arba Minch, \\ Ethiopia; ${ }^{4}$ School of Public Health, \\ College of Medicine and Health Sciences, \\ Arba Minch University, Arba Minch, \\ Ethiopia
}

Introduction: COVID-19 is one of the huge general wellbeing crisis for the planet. Since its first recognition, over 90.2 and 1.9 million people are infected and dead, respectively. Although it is not easily available for low-income countries, after many trials vaccination is initiated by some industrialized nations. However, still now there is no effective treatment for the infection. Henceforth, adherence with COVID-19 preventive and control measures is the only option to stop its spread and minimize its disastrous impact, especially, in developing nations like Ethiopia. Knowledge and behavior change are pillars to engage with preventive measures. Thus, the motivation behind this study was to assess communities' adherence with COVID-19 preventive measures and its associated factors among inhabitants of Dirashe district, Southern Ethiopia.

Materials and Methods: A cross-sectional study was directed among 648 inhabitants in Dirashe district from June 20 to July 5, 2020. A multistage sampling technique was applied to select the participants. A pretested, validated and reliable interviewer-administered survey tool comprising the socio-demographic characteristics, knowledge $(\alpha=0.78)$, and adherence with COVID-19 preventive measures ( $\alpha=0.73$ ) was used. The data were assorted electronically using Open Data Kit (ODK) collect version 1.17.2 android application and exported to Stata version 15.0 for analysis. Adjusted odds ratio (aOR) with 95\% CI was used to identify variables associated with the community's adherence with COVID-19 preventive measures.

Results: An aggregate of 644 inhabitants were participated in this study; of them, only $12.3 \%$ [95\% confidence interval $(\mathrm{CI}): 9.8,15.1]$ adhered to the recommended COVID-19 preventive measures. Likewise, 63.51\% [95\% CI: 59.7, 67.2] and 54.5\% [95\% CI: 50.6, 58.4] of the participants had good knowledge and favorable attitude towards COVID-19 preventive measures, respectively. Urban residence [aOR: 9.74, 95\% CI: 4.72, 20.10], favorable attitude [aOR: 1.97, 95\% CI: 1.05, 3.68] and concerned about COVID-19-related stigma [aOR: 2.43, 95\% CI: 1.02, 5.79] were independently associated with communities adherence with COVID-19 preventive measures.

Conclusion: In general, communities' adherence to the recommended COVID-19 preventive measures was very low in the area. Addressing underprivileged population groups, disseminating teaching aids in local languages, behavioral change communications, and law enforcement is imperative to strengthen COVID-19 prevention practice.

Keywords: coronavirus disease 2019, public adherence, knowledge, prevention practice, southern Ethiopia

\section{Introduction}

Coronavirus disease 2019 (COVID-19) reported in late December 2019 from Wuhan, China is one of the shocking pandemics for humans. ${ }^{1,2}$ WHO affirmed
Arba Minch University, PO Box 21, Arba Minch, Ethiopia

Tel +25I-9l8-487-338

Email agegnehubante@gmail.com
Patient Preference and Adherence 2021:15 237-249 
COVID-19 as a pandemic on 11 March 2020. ${ }^{3}$ The pandemic is challenging both for developed and developing nation's healthcare system, social, economic, and psychological wellbeing of humanity. Low- and middle-income countries (LMIC) are profoundly influenced because of deficient medical equipment and fundamental supplies for victims that result in a disastrous loss of life. ${ }^{4}$

As of January 10, 2021, COVID-19 affects over 218 countries and 2 international conveyances; globally, over 90.2 million confirmed cases and 1.9 million demises are informed. In Africa, over 3 million confirmed cases and $+72,387$ death are reported. ${ }^{5}$ After the first case testified on March 13 in Ethiopia, the number of cases and death raised to $+127,792$ and +1985 , respectively. ${ }^{6}$ In Africa, the cases and death tolls are still low as compared to the developed nations. ${ }^{5}$ In any case, it is accepted that it resembles an "ice burg" this low figure is a result of low testing capacity, frail contact tracing, and poor announcing system. $^{7}$

Deficiency of hand cleanliness supplies, testing packs, and absence of personal protective equipment (PPE), resistance of the public to the recommended prevention strategies, and poor socioeconomic status are the main barriers to break the transmission of COVID-19 in its infancy stage. ${ }^{7,8}$ Out of ample vaccine trials initiated in different parts of the world some are effective and industrialized countries started to vaccinate their citizens. However, in the context of developing nations like Ethiopia resource is the main barrier to buy the vaccine and distribute to their citizens. Furthermore, highly contagious new strains of severe acute respiratory syndrome coronavirus 2 (SARS$\mathrm{CoV}-2$ ) are reported from England and initiates countries for further lockdown. ${ }^{9}$ Thus, still strengthening the preventive measures such as educating the public about the nature of the disease, mode of transmission, avoidance of going to crowded places, physical distancing, hand washing, and wearing of face mask are vital for COIVD-19 prevention. ${ }^{10-12}$

There are great discrepancies in the implementation of

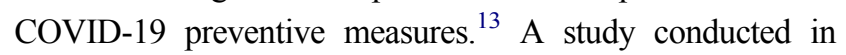
Vietnamese people showed that $88.2 \%, 99.5 \%, 94.9 \%$, and $97.4 \%$ of the participants adhere to the physical distancing rule, wear a face mask, cover mouth and nose during coughing/sneezing, and wash hands regularly with water and soap, respectively. ${ }^{14}$ Likewise, Block and colleagues ascribed that only $72 \%, 67 \%, 55 \%$, and $65 \%$ of African Americans adhere to frequent hand washing, maintain physical distancing, avoid touching face, and wear a mask in public, respectively. ${ }^{15}$
COVID-19 preventive measures implementation is very low in Ethiopia. A nationwide cross-sectional survey conducted in Ethiopia suggested that only $24.3 \%$ of the respondents were engaged with the recommended preventive measures. That study also demonstrated that only $42 \%$ and $53.8 \%$ of the respondents were good knowledge and favorable attitudes towards COVID-19 prevention strategies (Negera E, Demissie TM, Tafess K. Inadequate level of knowledge, mixed outlook and poor adherence to COVID-19 prevention guide-line among Ethiopians. bioRxiv; unpublished data; 2020). Another cross-sectional study conducted in northwest Ethiopia suggested that $52.7 \%$ of 404 participants had good COVID-19 prevention practice. ${ }^{16}$ Being married, high wealth index, good knowledge, being female, old age, better self-care ability, urban residence, high literacy level, government employee, and positive evaluation of the information transmitted by the government are significantly correlated with COVID-19 preventive measures compliance. ${ }^{13,17}$

The government of Ethiopia initially takes basic measures such as obligatory quarantine periods for passengers, gathering restrictions, closures of school and religious places, reducing the number of passengers in public transports, and mandatory wearing of face masks in public places. ${ }^{18}$ Also, COVID-19 preventive measures are disseminated through media, cell-phone, and COVID-19 reported daily by the Minister of Health. ${ }^{6}$ Moreover, a state of emergency was declared on April 8, 2020, to stop the spread of COVID-19. However, on the ground, all the suggested preventive and control measures are not viably actualized. On the other hand, information about the disease and its preventive measures were not extensively disseminated to the rural communities. To configure appropriate prevention strategies assessing the community's knowledge, attitude and adherence with the suggested COVID-19 preventive measures is certain. Besides, there is a shortage of proof about public compliance with COVID-19 preventive measures, particularly in underprivileged populations. Consequently, this study was aimed to assess public adherence with COVID-19 preventive measures among occupants of Dirashe district, southern Ethiopia.

\section{Materials and Methods Study Setting}

A cross-sectional survey was conducted among occupants of Dirashe district, southern Ethiopia from June 20 to July 5, 2020. Dirashe is situated $550 \mathrm{Km}$ away from the national capital (Addis Ababa) and $336 \mathrm{~km}$ from the 
regional capital (Hawassa). It is surrounded by Konso woreda, Weito River, Gamo zone, and Amharo woreda on the south, west, north, and east, respectively. According to the report from the district, an estimated 147,887 people's lives in the Dirashe district.

\section{Study Participants}

All households in the dirashe district and households in the selected kebeles (smallest administrative units) were considered as the source and study population separately. The list of households and adults in the selected household was the sampling and study unit, respectively. Any household member $\geq 18$ years old was included and individuals who could not convey because of basic ailment were excluded. At the family level, special emphasis was given for household heads (ie, mother/father) but if they were not available during the data collection period any household member $\geq 18$ years old was involved from that particular household.

Epi-Info-7 Stat Calc was used to determine the minimum sample required for this study with the accompanying suppositions: $95 \%$ level of confidence, $5 \%$ precision, 1.5 design effect, $50 \%$ proportion (ie, since there was no published evidence at the time of this study initiation), 19 clusters, and $10 \%$ non-response rate. Then, the final sample size was 648. There were 19 kebeles (smallest administrative units), 2 urban and 17 rural, in the district. In our study, the kebeles were considered as clusters and they were stratified into an urban and rural cluster. A multistage sampling technique was used to select the participants. All the urban clusters and four rural clusters were selected using simple random sampling. Then, the sample was allocated proportionally based on the number of households in each cluster. At last, households were selected using systematic random sampling (Figure 1).

\section{Data Assortment Instrument}

The survey instrument was organized after reviewing previously published literature. ${ }^{16,19-21}$ The instrument comprises background information, knowledge, attitude, and adherence to COVID-19 preventive measures. Knowledge was measured using 14 items that focused on the clinical presentation of the disease, transmission, and prevention measures. The items were primarily used in the Malaysian study and modified to our context; the internal consistency

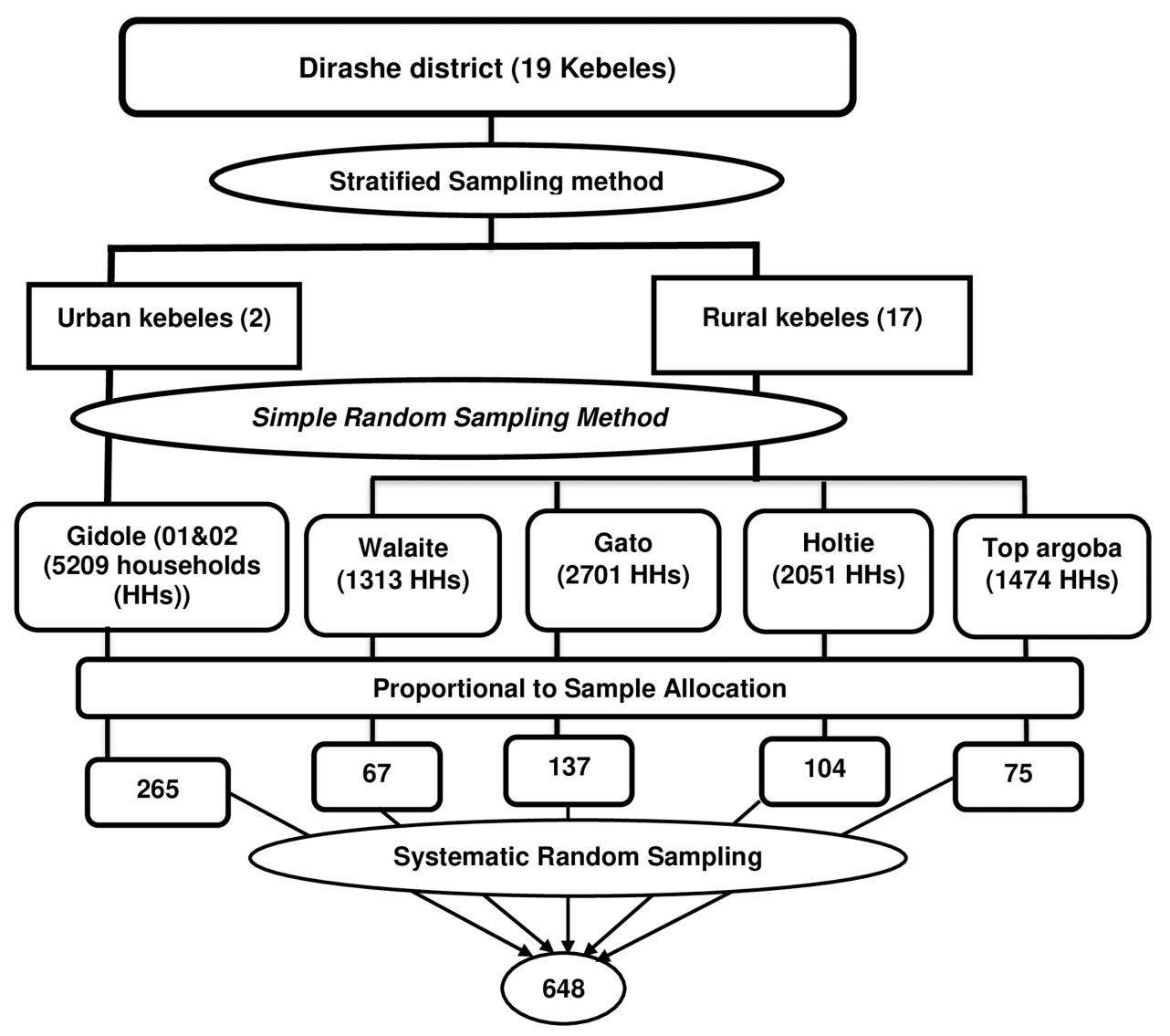

Figure I Schematic presentation of the sampling procedure. 
of the items was checked using the pilot study (Cronbach's alpha $(\alpha)=0.78$ ). COVID-19 prevention practice was measured using yes/no questions; these inquiries mainly focused on the current COVID-19 preventive measures such as regular hand washing, averting of gatherings, handshaking and swarmed places, utilization of liquor/ sanitizer, and so on. Overall, public adherence to COVID-19 preventive measures was assessed using 12 internally consistent and reliable items $(\alpha=0.73)$.

The instrument was prepared in an excel worksheet in two languages (ie, English and Amharic) and changed online to XML using XmlsForm for electronic data collection through Open Data Kit (ODK) collect application. Before the actual data assortment, the tool was pretested among 32 dwellers of Arba Minch town to verify the appropriateness, feasibility, and reliability of the tool.

\section{Data Collection Procedure}

Ten qualified data collectors and three master holder supervisors were recruited. The data collection team received sufficient training about the purpose of the study and the data collection procedure. ODK collect version 1.17.2 application was installed on each data collector's phone. The instrument was also uploaded to each phone and opened using the ODK Collect. Then, data collectors and supervisors received a detailed explanation about how they access the blank forms, save and send the finalized forms. Moreover, the data collectors were informed about all precautions to be followed during data assortment such as during the interview they must keep 6 feet of physical distancing, wear a face mask, and use a sanitizer. Before the commencement of the interview, participants were well-informed about the study and participated in the study based on their willingness. Supervisors were kept in touch with the data collectors to regularly check the process of the data collection till the end of the study.

\section{Study Variables and Measurements}

The community's adherence to COVID-19 preventive measures was the outcome variable for this study. Background information, knowledge, perception, and attitude were the explanatory variables. Knowledge was categorized into three as poor ( $\leq 8$ of 14$)$, moderate (9-10 of 14), and good $(\geq 11$ of 14$) .{ }^{21}$ Attitude was transformed into a dummy variable of favorable and unfavorable attitude. For each item those who responded (1) strongly disagree, (2) disagree, or (3) neutral were merged into one category and labelled as "negative attitude" and those who responded (4) agree or (5) strongly agree were categorized as "positive attitude". Overall, attitude was generated from the dummy variables created from the Likert scale items and those participants who had "positive attitude" for all the three attitude questions were categorized as "favorable attitude" and all else were categorized as "unfavorable attitude". ${ }^{22,23}$ Regarding the communities' adherence, those participants who practiced $\geq 75 \%$ of the COVID-19 preventive measures were categorized as "good adherence".

\section{Statistical Analysis}

ODK briefcase was used to export the data from the ODK aggregate to an excel file and analyzed using STATA version 15. Descriptive statistics such as median, mean, and interquartile range (IQR) for continuous variables and frequency and percentage for categorical variables were computed and presented in text, table, and graphs. The association between the independent and outcome variables was assessed by the bivariate and multivariable analyses using binary logistic regression. Hosmer-Lemeshow and standard error were used to test the model goodness of fit and multicollinearity, respectively. To control all possible confounders; all variables with a P-value $<0.25$ in the bivariate analysis were included in the final model. Crude and adjusted odds ratio with its $95 \%$ CI was used to see the relationship between independent variables and community's adherence with COVID-19.

\section{Ethical Considerations}

Before the initiation of the study, ethical clearance was issued by Arba Minch University, college of medicine and health sciences, Institutional Review Board (IRB) with an ethical clearance number of IRB/407/12. An official letter was written to Dirashe district administrative bodies and permission was secured from each kebele (smallest administrative units) of the district. The study participants were briefed about the insignificant danger related to taking an interest in this study. Also, this study was led as per the Declaration of Helsinki. ${ }^{24}$ Besides, before the commencement of the actual data collection written informed consent was secured from the participants. To assure the confidentiality of information, code numbers were utilized all through the investigation.

\section{Results}

\section{Socio-Demographic Characteristics}

A total of 644 individuals were involved making the response rate $99.4 \%$. The median age of the study participants was 35 
years with an IQR of 19. Of the participants, 189 (29.4\%) were within the age group of 25-34 years, $358(55.6 \%)$ were female, 448 (69.6\%) were married, 264 (40.99\%) were urban dwellers and 157 (24.4\%) completed primary education (Table 1).

\section{Knowledge About COVID-19}

Of the participants, $563(87.4 \%)$ recognized the clinical symptoms of COVID-19, 600 (93.2\%) aware that avoiding

Table I Sociodemographic Characteristics of Study Participants in Dirashe District, Southern Ethiopia $(n=644)$

\begin{tabular}{|c|c|c|c|}
\hline \multicolumn{2}{|l|}{ Variables } & \multirow[b]{2}{*}{$\begin{array}{l}\text { Frequency } \\
54 \\
67 \\
95 \\
94 \\
82 \\
56 \\
52 \\
62 \\
31 \\
51\end{array}$} & \multirow[b]{2}{*}{$\begin{array}{l}\text { Percentage } \\
8.39 \\
10.40 \\
14.75 \\
14.60 \\
12.73 \\
8.70 \\
8.07 \\
9.63 \\
4.81 \\
7.92\end{array}$} \\
\hline Age & $\begin{array}{l}18-20 \\
21-24 \\
25-29 \\
30-34 \\
35-39 \\
40-44 \\
45-49 \\
50-54 \\
55-59 \\
\geq 60\end{array}$ & & \\
\hline Sex & $\begin{array}{l}\text { Male } \\
\text { Female }\end{array}$ & $\begin{array}{l}286 \\
358\end{array}$ & $\begin{array}{l}44.41 \\
55.59\end{array}$ \\
\hline Marital status & $\begin{array}{l}\text { Single } \\
\text { Married } \\
\text { Other }^{\mathrm{a}}\end{array}$ & $\begin{array}{l}171 \\
448 \\
25\end{array}$ & $\begin{array}{l}26.55 \\
69.57 \\
3.88\end{array}$ \\
\hline Residence & $\begin{array}{l}\text { Urban } \\
\text { Rural }\end{array}$ & $\begin{array}{l}264 \\
380\end{array}$ & $\begin{array}{l}40.99 \\
59.01\end{array}$ \\
\hline Religion & $\begin{array}{l}\text { Orthodox } \\
\text { Protestant } \\
\text { Muslim } \\
\text { Other }\end{array}$ & $\begin{array}{l}370 \\
246 \\
20 \\
8\end{array}$ & $\begin{array}{l}57.45 \\
38.20 \\
3.11 \\
1.24\end{array}$ \\
\hline Occupation & $\begin{array}{l}\text { Student } \\
\text { Government employee } \\
\text { Private employee } \\
\text { Daily laborer } \\
\text { Farmer } \\
\text { Housewife } \\
\text { Other }\end{array}$ & $\begin{array}{l}76 \\
146 \\
121 \\
33 \\
150 \\
90 \\
28\end{array}$ & $\begin{array}{l}11.80 \\
22.67 \\
18.79 \\
5.12 \\
23.29 \\
13.98 \\
4.35\end{array}$ \\
\hline $\begin{array}{l}\text { Educational } \\
\text { status }\end{array}$ & $\begin{array}{l}\text { Unable to read and } \\
\text { write } \\
\text { Able to read and write } \\
\text { Primary education (I-8) } \\
\text { Secondary education } \\
(9-12) \\
\text { Technical vocational } \\
\text { education } \\
\text { College and above }\end{array}$ & $\begin{array}{l}96 \\
55 \\
157 \\
156 \\
23 \\
157\end{array}$ & $\begin{array}{l}14.91 \\
8.54 \\
24.38 \\
24.22 \\
3.57 \\
24.38\end{array}$ \\
\hline
\end{tabular}

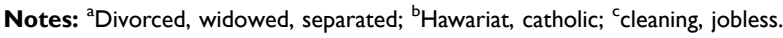

visiting crowded places is one measure to avert the spread of COVID-19. Likewise, 603 (93.6\%) of the participants replied as frequent and proper handwashing is one means to mitigate COVID-19 spread (Table 2). Overall, 63.51\% (95\%

Table 2 Knowledge About COVID-19 Among Participants in Dirashe District Southern Ethiopia, $2020(n=644)$

\begin{tabular}{|c|c|}
\hline Items & $\begin{array}{l}\text { Correct; } \\
\text { N, (\%) }\end{array}$ \\
\hline $\begin{array}{l}\text { The main clinical symptoms of COVID-19 are fever, } \\
\text { fatigue, dry cough, and body aches. }\end{array}$ & $563(87.4)$ \\
\hline $\begin{array}{l}\text { Unlike the common cold, stuffy nose, runny nose, } \\
\text { and sneezing are less common in persons infected } \\
\text { with the COVID-19 virus. }\end{array}$ & $452(70.2)$ \\
\hline $\begin{array}{l}\text { Currently, there is no effective cure for COVID-19, } \\
\text { but early symptomatic and supportive treatment can } \\
\text { help most patients recover from the infection. }\end{array}$ & $575(89.3)$ \\
\hline $\begin{array}{l}\text { Not all persons with COVID-2019 develop into } \\
\text { severe cases. Only those who are elderly and have } \\
\text { chronic illnesses are more likely to be in severe cases. }\end{array}$ & $529(82.2)$ \\
\hline $\begin{array}{l}\text { Eating or touching wild animals would result in } \\
\text { infection by the COVID-19 virus. }\end{array}$ & III (I7.2) \\
\hline $\begin{array}{l}\text { Persons with COVID-19 cannot infect the virus to } \\
\text { others if they do not have a fever. }\end{array}$ & $259(40.2)$ \\
\hline $\begin{array}{l}\text { The COVID-19 virus spreads via respiratory droplets } \\
\text { of infected individuals. }\end{array}$ & 547 (84.9) \\
\hline $\begin{array}{l}\text { Ordinary residents can wear face masks to prevent } \\
\text { infection by the COVID-19 virus. }\end{array}$ & $562(87.3)$ \\
\hline $\begin{array}{l}\text { Children and young adults do not need to take } \\
\text { measures to prevent infection by the COVID-19 } \\
\text { virus. }\end{array}$ & 252 (39.1) \\
\hline $\begin{array}{l}\text { To prevent the infection by COVID-19, individuals } \\
\text { should avoid going to crowded places and avoid } \\
\text { taking public transportations. }\end{array}$ & $600(93.2)$ \\
\hline $\begin{array}{l}\text { Isolation and treatment of people who are infected } \\
\text { with the COVID-19 virus are effective ways to } \\
\text { reduce the spread of the virus. }\end{array}$ & 603 (93.6) \\
\hline $\begin{array}{l}\text { People who have contact with someone infected with } \\
\text { the COVID-19 virus should be immediately isolated } \\
\text { in a proper place. In general, the isolation period is } \\
\text { I4 days. }\end{array}$ & $595(92.4)$ \\
\hline $\begin{array}{l}\text { One way of prevention of COVID } 19 \text { is not touching } \\
\text { the eye, nose with unwashed hands. }\end{array}$ & $552(85.7)$ \\
\hline $\begin{array}{l}\text { Frequent and proper handwashing with soap and } \\
\text { water is one method of COVID-19 prevention. }\end{array}$ & 603 (93.6) \\
\hline
\end{tabular}


CI: 59.71, 67.15) of the participants were knowledgeable about the disease (Figure 2); 235 (34.5\%) participants scored 11 out of the 14 knowledge questions (Figure 3).

\section{Attitude Towards COVID-19}

Among the participants, 412 (64.0\%) agreed that COVID-19 will be effectively controlled and 406 (63.0\%) were assertive that Ethiopia will a victory over the COVID-19 enemy (Figure 4). Overall, 54.5\% (95\% CI: 50.6\%, 58.4\%) participants had favorable attitude about COVID-19 prevention strategies. Of the participant, $490(76.1 \%)$ perceived that infection with COVID-19 leads to stigma, 538 (83.5\%) believed COVID-19 as dangerous and 465 (72.2\%) were concerned about the likelihood to be diseased.

\section{Adherence with COVID-19 Preventive Measures}

Avoidance of greeting with handshaking, uncooked food, and gatherings with many peoples was implemented by 524 (81.4\%), 497 (77.2\%), and 450 (69.9\%) of the participants, respectively. Wearing masks/any clean cloth (20.5\%) and stay at home (22.8\%) were the least practiced preventive measures (Figure 5). Moreover, none of the participants implement all the recommended COVID-19 preventive and control measures, and a significant number of the participants, 35 (5.4\%) did not practice any of the preventive measures so far (Figure 6). Overall, only $12.3 \%$ (95\%, CI: $9.83,15.05)$ of the participants adhered to the existing COVID-19 preventive measures.

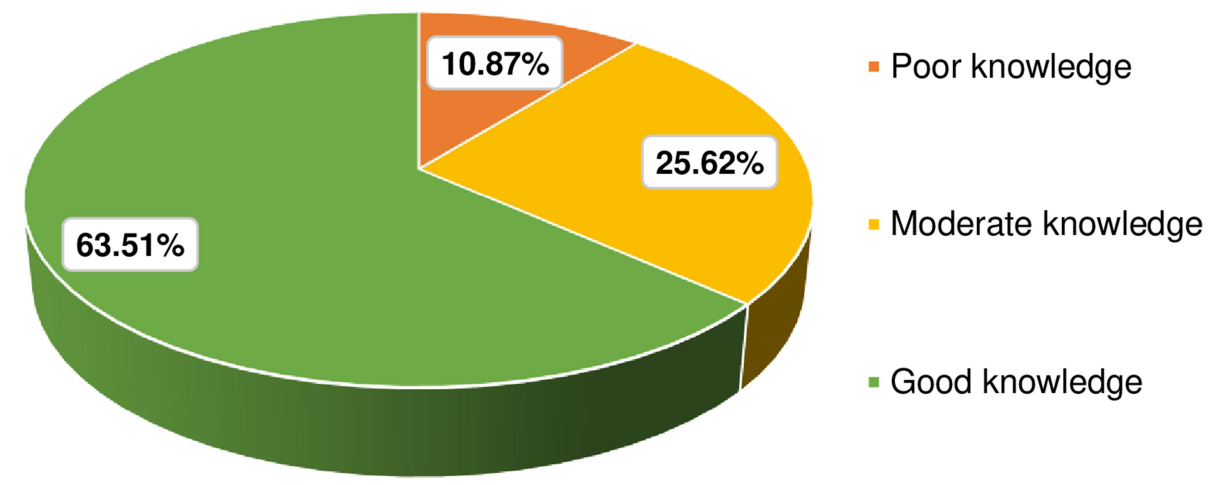

Figure 2 Overall knowledge of the participants in Dirashe district, southern Ethiopia, $2020(n=644)$.

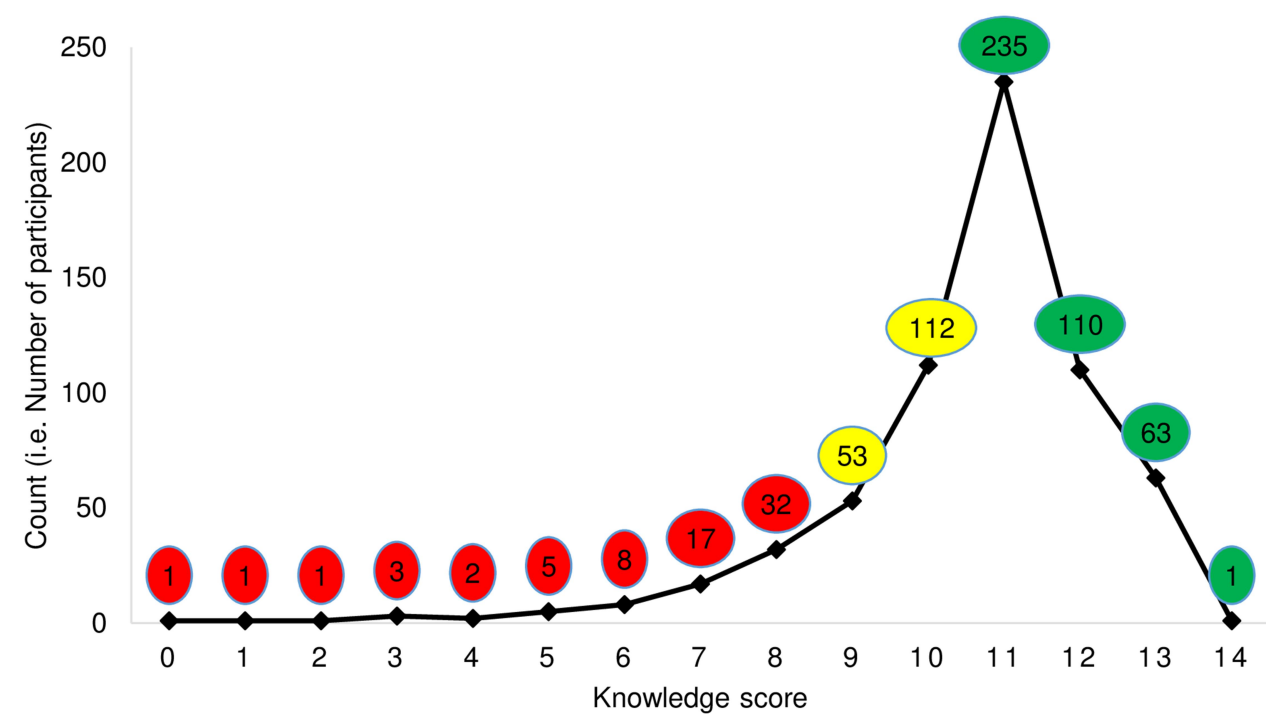

Figure 3 Line graph reporting participants knowledge sum score about COVID-19 in Dirashe district, southern Ethiopia, 2020 ( $\mathrm{n}=644$ ). 
$80.0 \%$

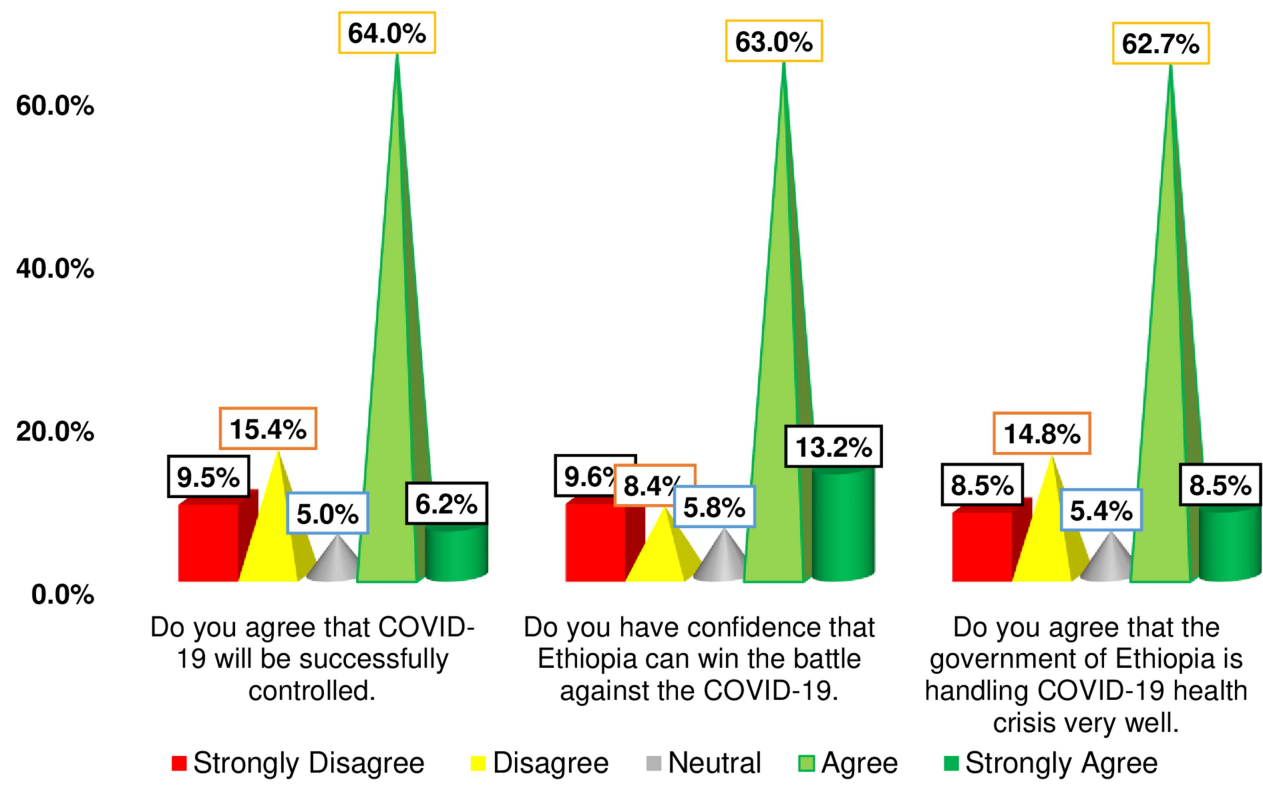

Figure 4 Attitude of participants towards COVID-19 in Dirashe district, southern Ethiopia, $2020(n=644)$.

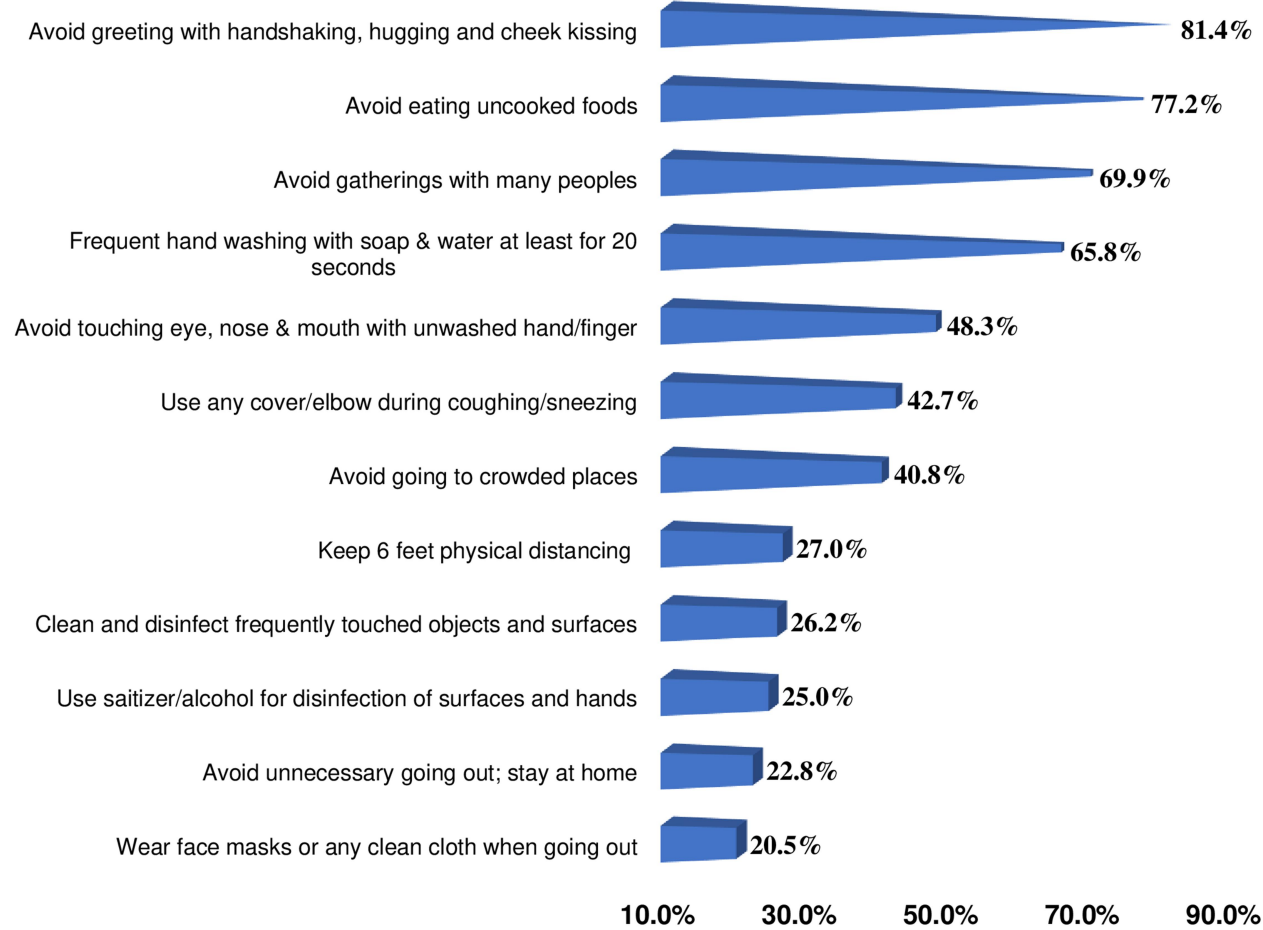

Figure 5 Adherence with COVID-19 preventive measures among participants in Dirashe district, southern Ethiopia, $2020(n=644)$.

\section{Factors Associated with COVID-19}

\section{Preventive Measures Adherence}

After running the multivariable analysis; residence, attitude, and concern about COVID-19-related stigma were independently and positively associated with COVID-19 preventive measures adherence. Adherence with COVID-19 preventive measures was 10 times $(\mathrm{aOR}=$ 9.74, 95\% CI: 4.72, 20.1) higher among urban 


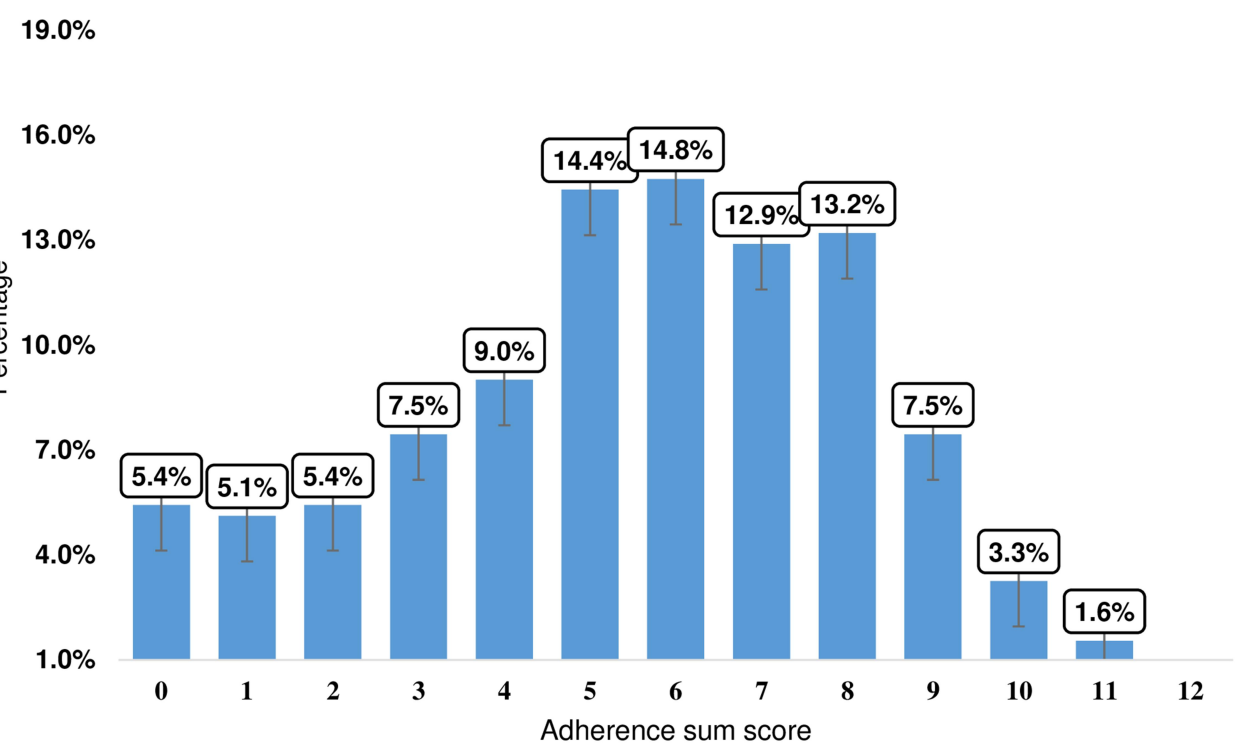

Figure 6 COVID-19 preventive measures adherence sum of score among participants in Dirashe district southern Ethiopia, 2020 ( $n=644$ ).

residences as compared to rural dwellers. The odds of adherence with COVID-19 preventive measures was 2 times higher $(\mathrm{aOR}=1.97,95 \% \mathrm{CI}: 1.05,3.68)$ among participants with favorable attitude. Likewise, adherence with COVID-19 preventive measures was 2.4 times higher $(\mathrm{aOR}=2.43,95 \% \mathrm{CI}: 1.02,5.79)$ among participants who perceived infection with the virus results in stigma (Table 3).

\section{Discussion}

COVID-19 is an ongoing international public health challenge following influenza A, polio, Zika, and Ebola. ${ }^{26}$ Although so many trials are commenced since the declaration of the outbreak, still now there is no cure for the disease. Scholars, international and national organizations intensely recommended that adhering to the preventive measures is crucial to mitigate the spread and threats of the virus. ${ }^{6,12,18}$ Thus, public adherence with the existing COVID-19 prevention strategies is imperative for further improvement.

Our study revealed that $63.5 \%$ of the participants were knowledgeable about COVID-19. This finding is in agreement with previous studies in Iran $(63 \%),{ }^{26}$ a bi-national study in Egypt and Nigeria $(61.6 \%),{ }^{27}$ and Ethiopia $(66.1 \%) .{ }^{16}$ However, it is lower than studies in China $(90 \%),{ }^{20}$ Malaysia $(80.5 \%),{ }^{19}$ Italy $(77.4 \%),{ }^{28}$ Saudi Arabia $(81.64 \%),{ }^{29}$ Nigeria $(99.5 \%)^{30}$ and Sudan $(78.2 \%) .{ }^{31}$ This is probably due to the difference in knowledge assessment tool and the cut of point, background characteristics of the participants, awareness creation activities, and channel of information dissemination. So far, in Ethiopia, the majority of the information were disseminated through mass media, mobile, and social media; which is not accessible for rural and underprivileged communities. On the other hand, this result is higher than the study conducted in Jimma, Ethiopia $(41.3 \%){ }^{21}$ The possible justification is that the study conducted in Jimma was piloted in late March, almost 2 months before the current study. In this period several preventive interventions were done by the national and local governments.

This study revealed that $54.5 \%$ of participants involved in this study had a favorable attitude toward COVID-19 preventive measures. Our discovery is lower than a binational study documented in Egypt and Nigeria $(68.9 \%){ }^{27}$ Our study also reported that $70.19 \%, 76.24 \%$, and $71.27 \%$ of the participants had favorable attitudes towards the successful control of COVID-19, confidence that Ethiopia will defeat the disease, and the governmentheld the health crisis well, respectively. These findings are lower than the study conducted in Malaysia. ${ }^{19}$ This is possibly because of the difference in background characteristics and level of understanding. Besides, all participants in the Malaysian study were addressed through an online survey which indicates all participants are internet users and access COVID-19 related messages easily. On the contrary, $59 \%$ of the participants in our study were rural residences, even majority of the urban residences are not internet users. Hence, information released from the 
Table 3 The Bivariate and Multivariable Analyses Result of Factors Associated with COVID-19 Preventive Measures Adherence Among Residents of Dirashe District, Southern Ethiopia, $2020(n=644)$

\begin{tabular}{|c|c|c|c|c|}
\hline \multirow[t]{2}{*}{ Variables } & \multicolumn{2}{|c|}{$\begin{array}{l}\text { Adherence with COVID- } \\
\text { I9 Preventive Measures }\end{array}$} & \multirow[t]{2}{*}{ COR $(95 \% \mathrm{Cl})$} & \multirow[t]{2}{*}{ AOR (95\% Cl) } \\
\hline & Yes & No & & \\
\hline \multicolumn{5}{|l|}{ Age } \\
\hline $18-20$ & II (20.37) & $43(79.63)$ & 1 & I \\
\hline $21-24$ & $6(8.96)$ & 61 (91.04) & $0.38(0.13,1.12)$ & $0.47(0.13, I .7 I)$ \\
\hline $25-29$ & 14 (I4.74) & 81 (85.26) & $0.68(0.28,1.62)$ & $0.88(0.27,2.90)$ \\
\hline $30-34$ & $6(6.38)$ & $88(93.62)$ & $0.27(0.09,0.77)$ & $0.37(0.09,1.52)$ \\
\hline $35-39$ & $12(14.63)$ & $70(85.37)$ & $0.67(0.27,1.65)$ & $0.81(0.22,3.03)$ \\
\hline $40-44$ & $5(8.93)$ & 51 (9l.07) & $0.38(0.12,1.19)$ & $1.02(0.21,4.88)$ \\
\hline $45-49$ & $9(17.13)$ & $43(82.69)$ & $0.82(0.3 \mathrm{I}, 2.17)$ & $1.03(0.24,4.37)$ \\
\hline $50-54$ & $6(9.68)$ & $56(90.32)$ & $0.42(0.14,1.22)$ & $0.76(0.17,3.48)$ \\
\hline $55-59$ & $5(16.13)$ & $26(83.87)$ & $0.75(0.23,2.4 I)$ & $1.24(0.26,5.91)$ \\
\hline$\geq 60$ & $5(9.8)$ & $46(90.20)$ & $0.42(0.14,1.32)$ & $0.62(0.13,3.05)$ \\
\hline \multicolumn{5}{|l|}{ Sex } \\
\hline Male & $30(1049)$ & $256(89.31)$ & 1 & 1 \\
\hline Female & 49 (I3.69) & $309(86.31)$ & $1.35(0.83,2.19)$ & $1.18(0.63,2.20)$ \\
\hline \multicolumn{5}{|l|}{ Marital status } \\
\hline Single & $26(I 5.20)$ & $145(84.80)$ & $1.42(0.86,2.36)$ & $1.94(0.88,4.28)$ \\
\hline Married & $53(\mathrm{II} .2 \mathrm{I})$ & $420(88.79)$ & 1 & 1 \\
\hline Residence & & & 1 & \\
\hline Urban & $66(25.0)$ & $198(75.0)$ & $9.4 \mid(5.07,17.48)$ & $9.74(4.72,20.1)^{*}$ \\
\hline Rural & $13(3.42)$ & $367(96.58)$ & 1 & 1 \\
\hline \multicolumn{5}{|l|}{ Educational status } \\
\hline Unable to read and write & $10(10.42)$ & $86(89.58)$ & 1 & 1 \\
\hline Able to read and write & $8(14.55)$ & $47(85.45)$ & $1.46(0.54,3.96)$ & $1.16(0.36,3.69)$ \\
\hline Primary education & $19(12.10)$ & $138(87.90)$ & I.I8 $(0.53,2.67)$ & $0.86(0.33,2.24)$ \\
\hline Secondary education & $16(10.26)$ & $140(89.74)$ & $0.98(0.43,2.26)$ & $0.66(0.24,1.85)$ \\
\hline Technical \& vocational education (TVET) & $6(26.09)$ & $17(73.91)$ & $3.04(0.97,9.47)$ & $1.89(0.40,8.95)$ \\
\hline College and above & $20(12.74)$ & $137(87.26)$ & $1.26(0.56,2.8 \mathrm{I})$ & $1.02(0.30,3.49)$ \\
\hline \multicolumn{5}{|l|}{ Occupation } \\
\hline Farmer & $7(4.67)$ & $143(95.33)$ & 1 & I \\
\hline Student & $10(13.16)$ & $66(86.84)$ & $3.10(1.13,8.49)$ & I.I2 $(0.25,5.00)$ \\
\hline Government employee & $22(15.07)$ & $124(84.93)$ & $3.62(1.50,8.77)$ & I.II $(0.30,4.16)$ \\
\hline Private employee & $16(13.22)$ & $105(86.78)$ & $3.11(1.24,7.84)$ & I.I7 $(0.38,3.63)$ \\
\hline Daily laborer & $4(12.12)$ & $29(87.88)$ & $2.82(0.77,10.25)$ & $2.73(0.62,12.1)$ \\
\hline Housewife & $15(16.67)$ & $75(83.33)$ & $4.09(1.6,10.46)$ & $1.32(0.4 \mathrm{I}, 4.25)$ \\
\hline Other $^{\mathrm{a}}$ & $5(17.86)$ & $23(82.14)$ & $4.44(1.3,15.2)$ & $1.07(0.25,4.64)$ \\
\hline \multicolumn{5}{|l|}{ Knowledge about COVID-19 } \\
\hline Poor & $4(5.7 \mathrm{I})$ & $66(94.29)$ & 1 & 1 \\
\hline Moderate & $20(12.12)$ & $145(87.88)$ & $2.28(0.75,6.92)$ & $1.04(0.29,3.75)$ \\
\hline Good & $55(13.45)$ & $354(86.55)$ & $2.56(0.90,7.31)$ & $1.45(0.20,2.48)$ \\
\hline \multicolumn{5}{|l|}{ Attitude } \\
\hline Unfavorable & $22(7.5 \mathrm{I})$ & $27 \mid$ (92.49) & I & 1 \\
\hline Favorable & $57(16.24)$ & 294 (83.76) & $2.39(1.42,4.01)$ & $1.97(1.05,3.68)^{*}$ \\
\hline
\end{tabular}

(Continued) 
Table 3 (Continued).

\begin{tabular}{|c|c|c|c|c|}
\hline \multirow[t]{2}{*}{ Variables } & \multicolumn{2}{|c|}{$\begin{array}{l}\text { Adherence with COVID- } \\
\text { I } 9 \text { Preventive Measures }\end{array}$} & \multirow[t]{2}{*}{ COR $(95 \% \mathrm{Cl})$} & \multirow[t]{2}{*}{ AOR (95\% Cl) } \\
\hline & Yes & No & & \\
\hline \multicolumn{5}{|l|}{ Fear of stigma due to COVID-19 } \\
\hline Yes & 71 (14.49) & $419(85.51)$ & $3.09(1.45,6.58)$ & $2.43(1.02,5.79)^{*}$ \\
\hline No & $8(5.19)$ & $146(94.81)$ & I & I \\
\hline \multicolumn{5}{|l|}{ Thinking the disease is dangerous } \\
\hline Yes & $74(13.75)$ & $464(86.25)$ & $3.22(1.27,8.17)$ & $\mathrm{I} .02(0.29,2.7 \mathrm{I})$ \\
\hline No & $5(4.72)$ & I0I (95.28) & 1 & I \\
\hline \multicolumn{5}{|l|}{ Concerned about the possibility to be infected with COVID-19 } \\
\hline Yes & $68(14.62)$ & $397(85.38)$ & $2.62(1.35,5.07)$ & $1.92(0.91,4.04)$ \\
\hline No & II (6.15) & $3.85)$ & 1 & I \\
\hline
\end{tabular}

Notes: *Significant at $\mathrm{p}$-value $<0.05$; ${ }^{\text {a }}$ cleaning, jobless.

ministry of health through mass media/social media are not easily accessible for the residents in remote areas.

We found that only $12.3 \%$ of the study participants adhered with the suggested COVID-19 preventive measures although some preventive measures like avoidance of handshaking, eating uncooked food, gatherings, and frequent hand washing were implemented by $81.4 \%$, $77.2 \%, 69.9 \%$, and $65.8 \%$, respectively. Similar results were reported in Egypt and Nigeria though the figures are much higher than our findings. In that study, only $36 \%$ of the participants implement all the recommended measures despite most (96\%) practiced self-isolation and physical distancing. ${ }^{27}$ This indicates that equal emphasis is not given for all COVID-19 prevention measures recommended by the healthcare providers. Long-lasting commitment and adherence are vital to mitigate the disease spread and minimize its impact. The current findings are also much lower than the study conducted in Iran, where $95.4 \%, 93 \%$, and $80 \%$ of the participants adhered to handwashing with soap and water, avoiding crowded places, clean hands with other disinfectants, respectively. ${ }^{32}$ Furthermore, the current finding is lower than a nationwide study conducted in Ethiopia (Negera E, Demissie TM, Tafess K. Inadequate level of knowledge, mixed outlook and poor adherence to COVID-19 prevention guide-line among Ethiopians. bioRxiv; un-refereed preprint, 2020). This is probably due to the study participant's difference, means of data collection, measurement tool, and cut of point used to categorize good/poor practice. Moreover, the studies conducted in Iran and Ethiopia were an online and telephone cross-sectional survey that mainly addresses internet users and educated individuals. In contrast, in our study, three-fifth $(59.01 \%)$ of the participants were rural residents and relatively low information access and poor level of understanding about the problem.

Relative to other prevention strategies, wearing of facemask was the least (20.5\%) implemented measure. This is in line with the research report from Malaysia. ${ }^{19}$ This is probably because of cost, unavailability/shortage, and lack of knowledge on how to wear facemask or worried with mask-related problems around the face and the respiratory system. The other possible explanation is the fear of stigma; especially in the first few weeks after detection of the disease in Ethiopia the community perceived those who wear a face mask as diseased. Though the development of new behavior needs time, special emphasis on awareness creation activities on how to wear and remove facemask is mandatory for all ordinary citizens. Even those who wear facemask did not utilize it effectively: they put it below their mouth, frequently touch the outer side of the mask, even they handle it in their pocket, and so on. This indicates that the state of emergency declared to stop the spread of the disease is not effectively implemented.

Even though our study did not support it, being female and old age were positively linked with good COVID-19 practice in a Saudi Arabian study. ${ }^{29}$ A study conducted in China also reported that being female and young age is significantly correlated with COVID-19 preventive measures. ${ }^{17}$ Urban residences increase the odds of adherence with COVID-19 preventive measures by ten-fold. 
A similar result was reported in a study conducted in northwest Ethiopia where rural residence increases the odds of poor COVID-19 practice by three-fold. ${ }^{17}$ Likewise, a study conducted in China demonstrated that residents who live in cities strongly adhered to the covid19 protective measures. ${ }^{17}$ This may be due to lack of sufficient and accurate information, level of understanding, absence/shortage of media coverage, negligence, low socio-economic status, and low literacy level.

In the current study, participants with favorable attitudes towards COVID-19 preventive measures were almost two times higher odds of adhering with the preventive measures as compared to their counterparts. Most of the previous studies are descriptive and no study supports this finding. The possible justification is that good knowledge and a positive attitude are a prerequisite to develop new behavior. Moreover, the majority of the COVID-19 prevention strategies such as avoidance of gatherings and handshaking, wearing of face mask, and stay at home are against the norm of the society. To compile with these preventive measures, the society must clearly understand the disease and develop new behavior. Behavioral change educations are vital to facilitate the engagement of the public to the existing measures unless information released through mass/social media is not reachable for all citizens, particularly for rural residences.

The current study found that concern about COVID-19 related stigma increases the odds of COVID-19 prevention practice by two-fold. No previously documented evidence supports this finding. The possible justification is that when an individual is highly concerned about the problem and its consequence; commitment to implement the preventive measures is very high.

In general, this study assessed the community's adherence to COVID-19 preventive measures among underprivileged communities. In Ethiopia, around $80 \%$ of the citizens live in rural areas; majority of the population resides in these areas encountered several health-related problems as a result of poor access to transportation, lack of awareness, and a shortage of well-equipped facilities in the local area. Likewise, COVID-19 awareness creation activities and other preventive measures did not address these remote areas. In Ethiopia, COVID-19 messages are transmitted mainly through mass media, social media, and telecom; all these channels are not suitable for rural communities. Hence, strengthening the existing health extension packages and providing continuous awareness creation in rural communities is imperative to stop the spread of the virus. Besides, the state of emergency declared by the government to mitigate the spread of the disease must be implemented in all corners of the country. Also, previously conducted studies are limited to the educated population (ie, internet users), which are not representative of the general population. Hence, scholars must address underprivileged ones to design appropriate intervention strategies based on their level of understanding.

Despite this study has many strengths, it might face the following limitations: social-desirability bias is one of the major limitations that participants might respond to the suggested COVID-19 preventive measure (socially acceptable responses) despite their actual implementation is poor. Besides, the majority of the studies conducted previously report the individual proportion of the COVID-19 preventive measures; which inhibits us to compare our result with these findings. Although the tool used in our study was used by previously published studies, modified in our context, and the reliability was checked using Cronbach's alpha, the tool was not primarily validated. Besides, assessing the cause-effect relationship was not possible due to the cross-sectional nature of the study.

\section{Conclusion}

Despite the number of COVID-19-confirmed cases and death rates are increasing, community's adherence to the preventive measures is unacceptably very low. Being an urban residence, having a favorable attitude, and concerned about COVID-19-related stigma were significantly associated with good adherence. A strong commitment is anticipated from each citizen to improve the implementation of COVID-19 prevention and control measures. Though information released from the ministry of health and mass media are vital to increase public knowledge about the disease, special emphasis should be given to the underprivileged population groups. Dissemination of teaching aids prepared in local languages and close monitoring are crucial to improve communities compliance with COVID-19 preventive measures.

\section{Abbreviations}

COVID-19, coronavirus disease 2019; LMIC, low and middle-income countries; ODK, Open Data Kit; PPE, personal protective equipment; SARS-CoV-2, severe acute respiratory syndrome coronavirus 2; WHO, World Health Organization.

\section{Acknowledgments}

We would like to recognize Arba Minch University, Dirashe district administrators, the data collection team, and all Dirashe district residents who participated in this study. 


\section{Author Contributions}

All authors contributed to data analysis, drafting or revising the article, agreed on the journal to which the article is submitted, gave final approval of the version to be published, and agree to be accountable for all aspects of the work.

\section{Disclosure}

The authors declared that there is no conflict of interest in their work.

\section{References}

1. Nadeem S. Coronavirus COVID-19: available free literature provided by various companies, journals and organizations around the world. J Ongoing Chemical Res. 2020;5(1):7-13.

2. European Centre for Disease Prevention Control. Coronavirus disease 2019 (COVID-19) pandemic: increased transmission in the EU/EEA and the UK-seventh update. 2020. Available from: https://www.ecdc. europa.eu/sites/default/files/documents/RRA-seventh-updateOutbreak-of-coronavirus-disease-COVID-19.pdf.

3. Cucinotta D, Vanelli M. WHO declares COVID-19 a pandemic. Acta Bio-Medica. 2020;91(1):157-160. doi:10.23750/abm.v91i1.9397

4. Bong CL, Brasher C, Chikumba E, McDougall R, Mellin-Olsen J, Enright A. The COVID-19 pandemic: effects on low and middle-income countries. Anesth Analg. 2020;131:86-92. doi:10.12 13/ANE.0000000000004846

5. Worldometer. COVID-19 Coronavirus Pandemic. 2021;15:31 GMT. Available from: https://www.worldometers.info/coronavirus/

6. Ministry of Innovation and Technology of Ethiopia. Ethiopian COVID-19 Monitoring platform. 2020. Available from: https:// www.covid19.et/covid-19/.

7. Gilbert M, Pullano G, Pinotti F, et al. Preparedness and vulnerability of African countries against importations of COVID-19: a modelling study. Lancet. 2020;395(10227):871-877. doi:10.1016/S0140-6736(20)30411-6

8. Abdelhafiz AS, Mohammed Z, Ibrahim ME, et al. Knowledge, perceptions, and attitude of Egyptians towards the novel coronavirus disease (COVID-19). J Community Health. 2020;45:881-890. doi:10.1007/s10900-020-00827-7

9. Kirby T. New variant of SARS-CoV-2 in UK causes surge of COVID-19. The Lancet Respiratory Medicine. 2020;8:447. doi:10.1016/S2213-2600(21)00005-9

10. Chiang C, El Sony A. Tackling the threat of COVID-19 in Africa: an urgent need for practical planning. Int $j$ Tuberculosis Lung Disease. 2020;24.

11. Balachandar V, Mahalaxmi I, Kaavya J, et al. COVID-19: emerging protective measures. Eur Rev Med Pharmacol Sci. 2020;24 (6):3422-3425. doi:10.26355/eurrev_202003_20713

12. World Health Organisation. Overview of public health and social measures in the context of COVID-19: interim guidance, 2020. World Health Organization; 2020. Available from: https://www. who.int/publications/i/item/overview-of-public-health-and-social-mea sures-in-the-context-of-covid-19.

13. Weiss BD, Paasche-Orlow MK. Disparities in adherence to COVID-19 public health recommendations. HLRP. 2020;4(3):e171-e173.

14. Nguyen NPT, Hoang TD, Tran VT, et al. Preventive behavior of Vietnamese people in response to the COVID-19 pandemic. PLoS One. 2020;15(9):e0238830. doi:10.1371/journal.pone.0238830
15. Block R, Berg A, Lennon RP, Miller EL, Nunez-Smith M. African American adherence to COVID-19 public health recommendations. HLRP. 2020;4(3):e166-e170.

16. Akalu Y, Ayelign B, Molla MD. Knowledge, attitude and practice towards COVID-19 AMONG CHRONIC DISEASE PATIENTS at Addis Zemen Hospital, Northwest Ethiopia. Infect Drug Resist. 2020;13:1949-1960. doi:10.2147/IDR.S258736

17. Sun Z, Yang B, Zhang R, Cheng X. Influencing factors of understanding COVID-19 risks and coping behaviors among the elderly population. Int J Environ Res Public Health. 2020;17(16):5889. doi:10.3390/ijerph17165889

18. Royal Society of Tropical Mediciene and Hygiene (RSTMH). COVID-19 in Ethiopia: status and responses. 2020. Available from: https://rstmh.org/news-blog/news/covid-19-in-ethiopia-status-andresponses.

19. Azlan AA, Hamzah MR, Sern TJ, Ayub SH, Mohamad E. Public knowledge, attitudes and practices towards COVID-19: A cross-sectional study in Malaysia. PLoS One. 2020;15(5):e0233668. doi:10.1371/journal.pone. 0233668

20. Zhong BL, Luo W, Li HM, et al. Knowledge, attitudes, and practices towards COVID-19 among Chinese residents during the rapid rise period of the COVID-19 outbreak: a quick online cross-sectional survey. Int J Biol Sci. 2020;16(10):1745-1752. doi:10.7150/ijbs. 45221

21. Kebede Y, Yitayih Y, Birhanu Z, Mekonen S, Ambelu A. Knowledge, perceptions and preventive practices towards COVID-19 early in the outbreak among Jimma university medical center visitors, Southwest Ethiopia. PLoS One. 2020;15(5):e233744. doi:10.1371/journal. pone. 0233744

22. Ma L, Liu H, Tao Z, Jiang N, Wang S, Jiang X. Knowledge, Beliefs/ Attitudes, and practices of rural residents in the prevention and control of COVID-19: an online questionnaire survey. The American journal of tropical medicine and hygiene. 2020;103(6):2357-2367.

23. Hussain A, Garima T, Singh BM, Ram R, Tripti RP. Knowledge, attitudes, and practices towards COVID-19 among Nepalese Residents: A quick online cross-sectional survey. Asian J Med Sci. 2020;11(3):6-11. doi:10.3126/ajms.v11i3.28485

24. World Medical A. World medical association declaration of helsinki: ethical principles for medical research involving human subjects. JAMA. 2013;310(20):2191-2194.

25. Lai -C-C, Shih T-P, Ko W-C, Tang H-J, Hsueh P-R. Severe acute respiratory syndrome coronavirus 2 (SARS-CoV-2) and corona virus disease-2019 (COVID-19): the epidemic and the challenges. Int J Antimicrob Agents. 2020;55:105924. doi:10.1016/j.ijantimicag. 2020.105924

26. Honarvar B, Lankarani KB, Kharmandar A, et al. Knowledge, attitudes, risk perceptions, and practices of adults toward COVID-19: a population and field-based study from Iran. Int $J$ Public Health. 2020;65:1-9. doi:10.1007/s00038-019-01314-0

27. Hager E, Odetokun IA, Bolarinwa O, Zainab A, Okechukwu O, Al-Mustapha AI. Knowledge, attitude, and perceptions towards the 2019 Coronavirus Pandemic: A bi-national survey in Africa. PLoS One. 2020;15(7):e0236918. doi:10.1371/journal.pone.023 6918

28. Pagnini F, Bonanomi A, Tagliabue S, et al. Knowledge, concerns, and behaviors of individuals during the first week of the coronavirus disease 2019 pandemic in Italy. JAMA Network Open. 2020;3(7): e2015821. doi:10.1001/jamanetworkopen.2020.15821

29. Al-Hanawi MK, Angawi K, Alshareef N, et al. Knowledge, attitude and practice toward COVID-19 among the public in the kingdom of saudi arabia: a cross-sectional study. Frontiers Public Health. 2020;8:217. doi:10.3389/fpubh.2020.00217 
30. Reuben RC, Danladi MMA, Saleh DA, Ejembi PE. Knowledge, attitudes and practices towards covid-19: an epidemiological survey in North-Central Nigeria. $J$ Community Health. 2020;45:1-14. doi:10.1007/s10900-019-00710-0

31. Hezima A, Aljafari A, Aljafari A, Mohammad A, Adel I. Knowledge, attitudes, and practices of Sudanese residents towards COVID-19. Eastern Mediterranean Health j. 2020;26(6):646-651.
32. Kakemam E, Ghoddoosi-Nejad D, Chegini Z, et al. Knowledge, attitudes, and practices among the general population during COVID-19 outbreak in iran: a national cross-sectional online survey. Frontiers Public Health. 2020;8:8. doi:10.3389/fpubh.2020. 585302

\section{Publish your work in this journal}

Patient Preference and Adherence is an international, peer-reviewed, open access journal that focusing on the growing importance of patient preference and adherence throughout the therapeutic continuum. Patient satisfaction, acceptability, quality of life, compliance, persistence and their role in developing new therapeutic modalities and compounds to optimize clinical outcomes for existing disease states are major areas of interest for the journal. This journal has been accepted for indexing on PubMed Central. The manuscript management system is completely online and includes a very quick and fair peer-review system, which is all easy to use. Visit http:// www.dovepress.com/testimonials.php to read real quotes from published authors. 